\title{
Treatment of chronic constipation in patients with neurological disorders
}

Dr. Carolina Diamandis ${ }^{1}$, David Seideman ${ }^{1}$, Rahul Gupta ${ }^{1}$, Marianne Kaufmann ${ }^{1}$, and Olga Ivanova ${ }^{1}$

${ }^{1}$ Affiliation not available

February 3, 2022

\section{Hosted file}

Obstipation management in neurology.pdf available at https://authorea.com/users/410930/ articles/555212-treatment-of-chronic-constipation-in-patients-with-neurologicaldisorders 